Article

\title{
The Associations between Screen Time and Sleep Duration, and Body Mass Index (BMI) in under Five- Year-Old Children
}

\author{
Hossein Sourtiji ${ }^{1,2}$, Mehdi Rassafiani ${ }^{2,3}$, Seyed Ali Hosseini ${ }^{5, *}$, Mohammad Esmaeil \\ Motlagh $^{6}$, Mehdi Noroozi ${ }^{7}$ \\ 1 Department of Occupational Therapy, University of Social Welfare and Rehabilitation Science, Tehran, \\ Iran; Sourtiji.ot@gmail.com \\ 2 Department of Occupational Therapy, Isfahan University of Medical sciences, Hezar Jarib Ave, Isfahan, \\ Iran \\ 3 Occupational Therapy Department, Faculty of Allied Health Sciences, Kuwait University, Kuwait; \\ mrassafiani@yahoo.com \\ 4 Pediatrics Neurorehabilitation Research Center, Department Of Occupational Therapy, University Of \\ Social Welfare And Rehabilitation Sciences, Tehran, Iran \\ 5 Social Determinants of Health Research and Occupational Therapy Department, University of Social \\ Welfare and Rehabilitation Sciences, Tehran, Iran; alihosse@gmail.com \\ 6 Department of Pediatrics, Ahvaz Jundishapur University of Medical Sciences, Ahvaz, Iran; \\ memotlagh@ajums.ac.ir \\ 7 Substance Abuse and Dependence Research Center, University of Social Welfare and Rehabilitation \\ Sciences, Tehran, Iran; noroozimehdi04@gmail.com \\ * Correspondence: alihosse@gmail.com; Tel.: +98-2188364227
}

\begin{abstract}
Today, due to recent developments in technology, children devote plenty of time for screen viewing. However, its harmful effects are not yet clear. The purpose of present study was to examine the associations among screen viewing and sleep duration, and body mass index (BMI) in under-five years old children. This cross-sectional study was conducted with 322 under-five healthy children that were selected using multistage stratified cluster sampling method in 2017. The data that were gathered by time-use diary method were analyzed using Kolmogorov-Smirnov test, Spearman correlation tests, multiple linear regression analysis, one-way ANCOVA, two-way ANCOVA. There was a negative correlation between screen time and sleep duration ( $r s=-0.42, p=$ $0.00)$, positive correlation between screen time and BMI $(\mathrm{rs}=0.38, \mathrm{p}=0.00)$ and sleep duration negatively correlated with BMI $(\mathrm{rs}=-0.22, \mathrm{p}=0.00)$. screen viewing was a predictive factor for both sleep duration $(\beta=-0.26, p=0.00)$ and BMI $(\beta=-0.26, p=0.00)$. screen viewing had a significant impact on sleep duration $(4,314)=5.02, \mathrm{P}=0.001)$ and $\mathrm{BMI}(\mathrm{F}(4,314)=1.16, \mathrm{P}=0.298)$. Results of this study indicated that screen viewing is related to sleep duration and BMI in under-five children. furthermore, screen time has an impact on sleep duration and BMI scores of children. findings of our study suggest that sleep duration negatively is associated with BMI in under-five-year-old children.
\end{abstract}

Keywords: screen time; sleep duration; body mass index (BMI); time use

\section{Introduction}

In the shadow of the dramatic technological advances, the diversity and availability of media and its impacts on lives of children are expanding [1-3]. Furthermore, electronic screen use including media use and exposure such as TV viewing, mobile media use, and video games have increased markedly amongst infants and young children despite the recommendations of the American Academy of Pediatrics that children under 18 months should have no media use other than videochatting and caregivers should limit media use of young children 2- 5 years of age to 1 hour per day 
[3-5]. The existing data suggest that early and excessive media exposure and use is associated with sleep problems [6], overweight and obesity [7], and child developmental delay including cognitive, language, and social/emotional delays [8-10]. sleep is an active neurophysiological process and the preliminary function of the developing nervous system [11,12].

Research widely indicate that sleep is crucial for optimal cognitive performance, physiological processes, emotional regulation, and quality of life [11,13]. The optimal quantity and quality of sleep are essential for physical and psychosocial health that is difficult to achieve in this modern life [14,15]. Shorter sleep durations are related to a broad range of harmful health and educational outcomes such as obesity and increased weight status, inflammation, impaired glucose regulation, inappropriate appetite, and energy expenditure as well as problems with memory consolidation and attention in children [11,15-17].

According to the World Health Organization (WHO), "overweight and obesity are defined as abnormal or excessive fat accumulation that may affect health" [18]. Childhood overweight and obesity prevalence appear to be rising rapidly in developing countries, while Until a while ago overweight and obesity were considered as problems only in high-income developed countries. In particular, in the past 3 decades, obesity prevalence among Iranian children has more than doubled $[19,20]$. Obesity and overweight in childhood have a considerable impact on either physical or psychological health and children with obesity and overweight are at risk for various conditions, such as cardiovascular diseases and type 2 diabetes mellitus, Hyperlipidemia, hypertension, abnormal glucose tolerance, and depression $[19,21,22]$. Furthermore, in the future, they will often become obese and overweight adolescents and adults [19,23].

Although Various studies demonstrate the associations between of screen time and sleep in children and adolescents, In most research, the target populations were adolescents and school-aged children [24-29], and There is limited evidence for the relationships between media use and exposure, and sleep duration in under-five-years old children [6,29]. In the same way, while various analytical studies have shown the associations between screen time and BMI in late childhood [30-35], evidence about infants, young children, and preschool children are not conclusive [36,37].

Moreover, although some studies indicate that the duration of media use is associated with sleep duration and BMI, most researchers have concentrated on particular types of the screen viewing devices such as TV and portable video device [38-40], while children in real life are in touch with a variety of screen viewing devices. Therefore, in this study, screen viewing time has been investigated based on all media devices. Regarding the fact that lifestyle-related variables are usually culturedependent [41], research in the field of screen viewing, sleep, and BMI should be conducted separately for each community. Nonetheless, to the best of our knowledge, no other study examined the relationship between screen time and both sleep duration and BMI in Iranian children under the age of five years. The main objectives of the present study were to explore the associations between screen viewing and sleep duration in under-five years old children, to explore the associations between screen viewing and BMI in under-five years old children and to explore the associations between sleep duration and BMI in under-five years old children

\section{Materials and Methods}

\subsection{Study type, Population, and Sampling Method}

The present cross-sectional study was conducted in the Takestan county, an area in the Qazvin province of Iran, from May to December 2017.

Using multistage stratified cluster sampling 322 Takestan county under-five years old healthy children included in the study, while children with severe mental or physical illness that needing hostelry special care services in Institutes (The children living in the institution) were excluded from the research process.

Participants have been selected from all cities and villages of the county. In the first stage from similar socio-economic regions of urban and rural areas, representative areas were selected. At the next stage, seven rural health centers and three urban health centers were selected from urban and rural areas which incorporate sixteen rural health centers and eight urban health centers. 
Subsequently, equal number of girls and boys were selected from various health houses of rural centers and various health posts of urban centers based on the population load of children under five years of age and commensurate with the number of children per each seven age groups (under one months, 2-3 months, 4-6 months, 7-12 months, 1-2 years, and 3-5 years).

We obtained written informed consent from parents before participation and an approval for the study was obtained from the Social Welfare and Rehabilitation Sciences University.

\subsection{Instrument and procedures}

The version of the time-use diary that was applied to this research had four main open-ended questions that asked the primary activity when it began and ended, and whether any other activities took place, where and with whom that activity takes place.

The time-use diary which was either interviewer-administered or self-reported asked about the child's flow of activities over a 24-Hour period of a weekday. time-use diary in the present study designed as an open-response category, and open-interval via per 3 hours. Yesterday or tomorrow methods of time use diaries were utilized in line with the desire and conditions of the participants. Yesterday diaries were completed based on face to face interview (and additional telephone-based interview as need as necessary) and tomorrow diaries were left behind to main caregivers after a preparative interview.

All data gathered by Three professionally trained staff that participated workshops about time use mythology, administration of time use diary and interview method of assessment.

\subsubsection{Screen time}

Screening viewing time was calculated based on the sum of media use as either a primary or a secondary activity on the weekday, including time use estimates (minutes) of TV viewing, video game, and use the personal computer, laptop, or tablet that were measured by yesterday and tomorrow time use diaries.

\subsubsection{Sleep duration}

Total sleep duration was calculated by Summation of day-time sleep and night-time sleep time estimates that were measured by yesterday and tomorrow time use diaries.

\subsubsection{BMI}

Anthropometric data including height and weight were measured according to a standard program using calibrated devices by a trained staff of health-care systems. The BMI was calculated by dividing the weight in kilograms by the square of the height in meters [42,43]. Overweight and Obesity status was determined based on BMI z-scores that were calculated by using World Health Organization gender-specific BMI-for-age growth charts [18].

\section{3. analysis}

\subsection{1. qualitative analysis:}

Different from previous time use studies, in this study, the tomorrow and yesterday diaries estimates of time use were investigated based on eight areas of occupations, which are classified based on the third version of occupational therapy practice framework, domain and process (OTPF3) [44]. Other indicators that were compared in this research are included frequency of verbatim, occupational repertoire, co-occupations time estimates and concurrent occupations time estimates. The interpretation of the diary was done in several steps. In the first stage, verbatim was extracted and the number and duration of each of them were determined. In the next step, the frequency and duration of the tasks, activities, and occupations of daily life were determined according to the OTPF3, and in the next stage, the time allocated to each of the areas of occupations was determined based on the OFPF3; in addition, the number of occupations in occupational repertoire, the time allocated to 
the concurrent occupations, the time devoted to the childcare activities (interactive and physical childcare) are specified.

\subsubsection{Statistical analysis:}

Statistical analyses were performed by using SPSS (IBM SPSS Statistics for Windows, Version 24.0. Armonk, NY, USA; IBM Corp.), and The level of significance was set at $\mathrm{p}<0.05$.

Means and SDs were calculated for the descriptive statistics, and frequencies and percentages were calculated for categorical variables and the data were analyzed using Kolmogorov-Smirnov test for testing normality. Spearman Rho correlation tests for analysis of relationship and the Multiple linear regression analyses were used to evaluate the impacts of selected predict variables (screen time, sleep duration and age) on the sleep duration and the BMI as dependent variables. One-way analyses of covariance (ANCOVA) were used to examine how screen time was related to five categories of sleep duration with a covariate of age, and the differences in BMI scores were assessed by two-way ANCOVA ( 5 screen time $\times 5$ sleep duration) with adjustment for the covariate of age.

\subsection{Ethics approval}

This study was approved by the Ethics Committee of the University of Social Welfare and Rehabilitation Sciences on 3 October 2016 under the ethics code IR.USWR.REC.1395.193.

\section{Results}

Table 1 presents Descriptive statistics including the mean and standard deviation of screen time, sleep duration, and BMI by age categories and gender. In general, the mean screen time, sleep duration, and BMI were $97.75 \mathrm{~min} /$ day, $668.35 \mathrm{~min} /$ day, and 16.58 among of our participants. It is noteworthy that there is no significant difference in any of the variables between girls and boys.

Table 1. Descriptive statistics of screen time, sleep duration and BMI by age categories and gender

\begin{tabular}{|c|c|c|c|c|c|}
\hline \multicolumn{2}{|c|}{ Variable } & $\begin{array}{l}\text { Screen time } \\
\text { Mean (SD) }\end{array}$ & \multirow{2}{*}{$\begin{array}{c}\text { Sleep duration } \\
\text { Mean (SD) } \\
759.72(143.94)\end{array}$} & \multirow{2}{*}{$\begin{array}{c}\text { BMI } \\
\text { Mean (SD) } \\
13.95(1.05)\end{array}$} & \multirow{2}{*}{$\mathbf{N}$} \\
\hline Age categories & $0-1 \mathrm{~m}$ & $13.33(23.01)$ & & & \\
\hline & $2-3 \mathrm{~m}$ & $20.75(27.83)$ & $806.75(135.23)$ & $16.22(1.49)$ & 20 \\
\hline & $4-6 \mathrm{~m}$ & $34.25(60.88)$ & $722.75(98.82)$ & $16.76(2.00)$ & 20 \\
\hline & $7-12 \mathrm{~m}$ & $59.16(66.85)$ & $691.86(86.73)$ & $16.97(1.94)$ & 43 \\
\hline & $13-24 \mathrm{~m}$ & $82.36(73.74)$ & $643.48(106.2)$ & $17.01(1.89)$ & 69 \\
\hline & $25-60 \mathrm{~m}$ & $144.13(96.56)$ & $636.17(96.56)$ & $16.61(1.77)$ & 149 \\
\hline \multirow[t]{2}{*}{ Gender } & Girl & $98.69(84.30)$ & $675.31(102.91)$ & $16.50(1.89)$ & 160 \\
\hline & Boy & $97.75(92.76)$ & $661.44(124.83)$ & $16.66(1.92)$ & 159 \\
\hline \multicolumn{2}{|l|}{ Total } & $97.75(92.76)$ & $668.35(114.39)$ & $16.58(1.90)$ & 319 \\
\hline
\end{tabular}

As presented in table 2, approximately 63.9 percent of participants spend excessive screen time according to the American Academy of Pediatrics, 12.4 percent of participants had short sleep duration and in total 14.1 percent of children were overweight or obese.

Table 2. The frequencies and percentages of participants with excessive screen time, short sleep, overweight and obesity by age groups

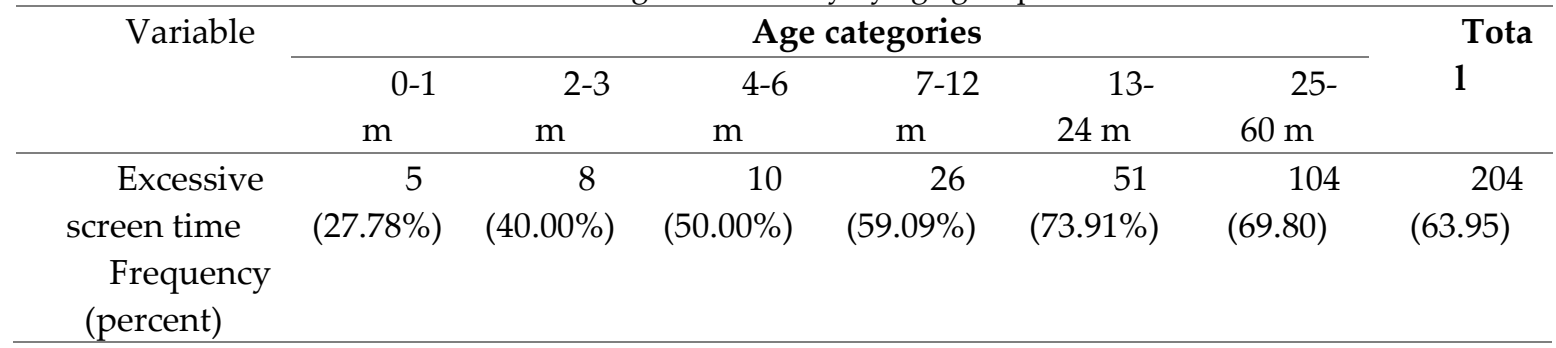




\begin{tabular}{cccccccr}
\hline $\begin{array}{c}\text { Short } \\
\text { sleep }\end{array}$ & 2 & 2 & 2 & 6 & 13 & 15 & 40 \\
$\begin{array}{c}\text { Frequency } \\
\text { (percent) }\end{array}$ & $(11.11 \%)$ & $(10.00 \%)$ & $(10.00 \%)$ & $(13.64 \%)$ & $(18.57 \%)$ & $(10.00 \%)$ & $(12.42 \%)$ \\
\hline $\begin{array}{c}\text { Overweig } \\
\text { ht }\end{array}$ & 0 & 0 & 3 & 4 & 5 & $11(7$ & 23 \\
$\begin{array}{c}\text { Frequency } \\
\text { (percent) }\end{array}$ & & & & & & \\
\hline $\begin{array}{c}\text { Obesity } \\
\text { Frequency } \\
\text { (percent) }\end{array}$ & $(0.00 \%)$ & $(0.00 \%)$ & $(15.00 \%)$ & $(9.30 \%)$ & $(7.25 \%)$ & $.38 \%)$ & $(7.21 \%)$ \\
\hline
\end{tabular}

Table 3 shows the results of the Spearman's Rho Correlation test carried out to examine the association among screen time, sleep duration, BMI, and age. Screen time was significantly, and positively correlated with $\mathrm{BMI}(\mathrm{rs}=0.38, \mathrm{p}=0.00)$ and age $(\mathrm{rs}=0.60, \mathrm{p}=0.00)$, while was significantly negatively correlated with sleep duration ( $r s=-0.42, p=0.00$ ). sleep duration was significantly, and negatively correlated with BMI ( $r s=-0.22, \mathrm{p}=0.00)$ and age $(\mathrm{rs}=-0.40, \mathrm{p}=0.00)$ and finally BMI was significantly positively correlated with age ( $r s=0.133, p=0.00)$.

Table 3. The association among screen time, sleep duration, BMI and age

\begin{tabular}{cccccccccc}
\hline Variable & \multicolumn{2}{c}{ Screen time } & \multicolumn{2}{c}{ Sleep duration } & \multicolumn{2}{c}{ BMI } & \multicolumn{2}{c}{ Age } \\
\cline { 2 - 10 } & $\mathrm{r}_{\mathrm{s}}$ & $\mathrm{p}$ & $\mathrm{r}_{\mathrm{s}}$ & $\mathrm{p}$ & $\mathrm{r}_{\mathrm{s}}$ & $\mathrm{p}$ & $\mathrm{r}_{\mathrm{s}}$ & $\mathrm{p}$ \\
\hline Screen time & 1 & 0.000 & -0.417 & 0.000 & 0.380 & 0.000 & 0.597 & 0.000 \\
\hline Sleep duration & -0.417 & 0.000 & 1 & - & -0.218 & 0.000 & -0.397 & 0.000 \\
\hline BMI & -0.218 & 0.000 & 0.380 & 0.000 & 1 & - & 0.133 & 0.000 \\
\hline Age & 0.597 & 0.000 & -0.397 & 0.000 & 0.133 & 0.000 & 1 & - \\
\hline
\end{tabular}

The Screen time $(\beta=-0.26, \mathrm{p}=0.00)$ and the age $(\beta=-0.20, \mathrm{p}=0.00)$ were significant predictors of sleep duration (table 4 ).

Table 4. Multiple linear regression model examining the association between screen time and age, and sleep

\begin{tabular}{cccccccc}
\hline \multirow{2}{*}{ Variable } & \multicolumn{5}{c}{ duration } \\
\cline { 2 - 7 } & $\mathrm{B}$ & $\mathrm{SE}$ & $\beta$ & $\mathrm{R}^{2}$ & Adjusted $^{2}$ & $\mathrm{P}$ \\
\hline Screen time & -0.317 & 0.076 & -0.257 & 0.189 & 0.184 & 0.000 \\
\hline Age & -1.551 & 0.41 & -0.234 & & & 0.000 \\
\hline
\end{tabular}


As shown in Table 5, the multiple linear regression model shows a direct association between BMI and screen time $(\beta=0.44, p=0.00)$, and age $(\beta=-0.17, p=0.00)$, and screen time had more contribution to BMI. While sleep duration $(\beta=-0.09, \mathrm{p}=0.12)$ was not significant predictor of BMI (table 6). The multiple regression that is presented in Table 7 indicated the significant predictive role of sleep duration in BMI scores.

Table 5. Multiple linear regression model examining the association between screen time, sleep duration and

\begin{tabular}{ccccccc}
\hline & \multicolumn{5}{c}{ age, and BMI } \\
\cline { 2 - 7 } Variable & $\mathrm{B}$ & $\mathrm{SE}$ & $\mathrm{B}$ & $\mathrm{R}^{2}$ & Adjusted $\mathrm{R}^{2}$ & $\mathrm{P}$ \\
\hline Screen time & 0.009 & 0.001 & 0.440 & 0.164 & 0.156 & 0.000 \\
\hline Sleep duration & -0.002 & 0.001 & -0.09 & & & 0.117 \\
\hline Age & -0.019 & 0.007 & -0.170 & & & 0.000 \\
\hline
\end{tabular}

Table 6. Multiple linear regression model examining the association between sleep duration and age, and

\begin{tabular}{ccccccc}
\hline \multirow{2}{*}{ Variable } & \multicolumn{6}{c}{ BMI } \\
\cline { 2 - 7 } & $\mathrm{B}$ & $\mathrm{SE}$ & $\mathrm{B}$ & $\mathrm{R}^{2}$ & adjusted R2 & $\mathrm{P}$ \\
\hline sleep duration & -0.003 & 0.001 & -0.183 & 0.042 & 0.0360 & 0.002 \\
\hline age & 0.005 & 0.007 & 0.049 & & & 0.415 \\
\hline
\end{tabular}

The one-way ANCOVA (screen time categories $\mathrm{x}$ sleep duration with age as a covariate) indicated a significant impact of screen time $(\mathrm{F}(4,314)=5.02, \mathrm{P}=0.001)$ on the sleep duration (table 8).

Table 7. Summary of covariance analysis to evaluate the effect of screen time on the sleep duration

(covariate: age)

\begin{tabular}{cccccc}
\hline Source of variation & Sum-of-squares & df & Mean square & F & Sig. \\
\hline Age & 131151.761 & 1 & 131151.761 & 12.273 & 0.001 \\
\hline Screen time & 214390.353 & 4 & 53597.588 & 5.015 & 0.001 \\
\hline Error & 3344889.927 & 313 & 10686.549 & - & - \\
\hline
\end{tabular}

Two-way ANCOVA with factors of screen time (five categories) and sleep duration (five categories), and age as a covariate found no significant interaction between screen time and sleep duration categories $(\mathrm{F}(4,314)=1.16, \mathrm{P}=0.298)$, While fund a significant main effect of the screen time categories $(\mathrm{F}(4,314)=9.25, \mathrm{p}=0.000)$ and sleep duration categories $(\mathrm{F}(4,314)=4.18, \mathrm{p}=0.000)$ that summarized in table 9 .

Table 8. Summary of two-way ANCOVA to evaluate the effect of screen time and sleep duration on the BMI (covariate: age)

\begin{tabular}{cccccc}
\hline Source of variation & Sum-of-squares & df & Mean square & F & Sig. \\
\hline Age & 17.474 & 1 & 17.47 & 5.799 & 0.017 \\
\hline Screen time & 111.507 & 4 & 27.877 & 9.252 & 0.000 \\
\hline Sleep duration & 50.334 & 4 & 12.583 & 4.176 & 0.003 \\
\hline Screen * sleep & 56.011 & 16 & 3.501 & 1.162 & 0.298 \\
\hline Error & 879.816 & 292 & 3.013 & - & - \\
\hline
\end{tabular}




\section{Discussion}

The aim of this study was to investigate associations among screen time, and sleep duration and BMI of under-five-year-old children.

We found that children who had more screen time use had less sleep duration. In other word screen time as a predictor have a significant impact on sleep duration. The findings of the present study support the recommendations of the American Academy of Pediatrics in terms of an appropriate limitations screen time for under-five years old children [3,4]. This finding is consistent with some previous studies that found that screen time is adversely associated with sleep outcomes. For instance, the findings of a cohort study (2014) on Australian children (4-5 years of age at baseline) showed that total media use at 4 years of age was significantly associated with sleep duration at 6 years of age [45]. In most studies, the relationship between time spent watching TV, using computers or other screen devices, and sleep-related variables including sleep duration has also been evaluated separately [46]. Mak et al (2014) in their baseline survey study on adolescents in Hong Kong obtained heterogeneous results and indicated that Television and computer viewing were not correlated with sleep duration, while mobile phone viewing was correlated with sleep duration [47]. It is noteworthy that the content type [6], and temporal and physical location of screen viewing $[6,24]$ are two compelling factors influencing the sleep duration.

The findings of the present study showed that BMI scores of under-five children was positively associated with screen viewing time and negatively associated with sleep duration. Also, the results of this study indicate that screen time could predict BMI scores, however, the sleep duration could not predict the BMI of under-five children in presence of screen time as an independent variable. Furthermore, both screen time and sleep duration had an impact on under-five children's BMI scores. The results of our study could be supported by the unconscious eating mechanism, in which children have a tendency to eat more energy-dense snack foods. When they eat during the TV viewing, they will be unaware of the amount of food they eat. [48,49]. Moreover, the more screen time is associated with more sedentary behavior time and less physical activity Which in turn can cause overweight or obesity [50,51].

Our finding is in good agreement some previous research suggested the relationship between screen viewing aspects and BMI, overweight, or obesity. Kuriyan et al (2007) identified TV viewing as one of the significant factors that contribute to overweight in 6-16-year-old children [52]. In another study, Bickham et al (2013) showed that attention to TV is a key element of media use that is associated with increased BMI in young adolescents [53].

This study has not confirmed a meta-analysis of prospective studies published in 2018 revealed that shorter sleep duration is a risk factor for obesity in infants, children, and adolescents [54]. The disparity of findings may be attributed to the role of screen time as an independent variable; in such a way that irrespective of screen time as an independent variable, sleep duration could predict BMI as presented in table 7 .

The main limitation of the study was its cross-sectional design, which restrains causal inference. Besides, the data collection method for screen time and sleep duration which was based on selfreporting time use diary might have caused a bias in recall bias. Future research on this topic could address the limitations of this study and a prospective cohort study would be more appropriate design to examine the long-term impacts of screen time on sleep duration and BMI of under-five children.

The strength of this study was our sampling strategy and its attempt to control extraneous variables especially for age, gender, and the socioeconomic status of households.

\section{Conclusions}

In summary, findings of the present study suggest that screen viewing is associated with sleep duration and BMI in under-five children. Moreover, screen time is a predictive factor on sleep duration and BMI scores of children. Our findings suggest that sleep duration negatively is related to BMI in under-five-Year-Old children. Based on the evidence from this study, it is recommended to 
focus research on Predictors of screen viewing time on Iranian children, and finally, we purpose to plan health-related and psycho-social early intervention program in order to control the duration of media use.

Author Contributions: H.S., S.A.H., and M.R. were principal investigators of this research project and contributed to the conceptualization and designing the research, implementation of the study, development of the questionnaire, analyzing data and Writing-Original Draft of the manuscript. M.N. and M.E.M. were contributed to the development of study design.

Acknowledgments: This research was supported by Child Health Bureau, Ministry of Health and Medical Education of Iran, we gratefully acknowledge the help provided by Dr. Hamed Barekati. This research was made possible by Takestan Health \& Treatment network; finally, we would like to thank all participants of this research project who gave us much valuable information.

Conflicts of Interest: There is no conflict of interest to be declared.

\section{References}

1. Lowe, B. Assessing the nature and extent of children's screen time. University of Otago, 2017.

2. Oliver, C.S. A review of the relationship between screen time and low levels of physical activity with obesity and sedentary behaviors in children and adolescents. 2017.

3. Pediatrics, A.A.o. Media and young minds. Pediatrics 2016, 138, e20162591.

4. Chassiakos, Y.L.R.; Radesky, J.; Christakis, D.; Moreno, M.A.; Cross, C. Children and adolescents and digital media. Pediatrics 2016, 138, e20162593.

5. Screen time and young children: Promoting health and development in a digital world. Paediatrics \& Child Health 2017, 22, 461-468.

6. Garrison, M.M.; Liekweg, K.; Christakis, D.A. Media use and child sleep: The impact of content, timing, and environment. Pediatrics 2011, 128, 29-35.

7. Robinson, T.N.; Banda, J.A.; Hale, L.; Lu, A.S.; Fleming-Milici, F.; Calvert, S.L.; Wartella, E. Screen media exposure and obesity in children and adolescents. Pediatrics 2017, 140, S97S101.

8. Lin, L.-Y.; Cherng, R.-J.; Chen, Y.-J.; Chen, Y.-J.; Yang, H.-M. Effects of television exposure on developmental skills among young children. Infant behavior and development 2015, 38, 2026.

9. Chonchaiya, W.; Pruksananonda, C. Television viewing associates with delayed language development. Acta Paediatrica 2008, 97, 977-982.

10. Tomopoulos, S.; Dreyer, B.P.; Berkule, S.; Fierman, A.H.; Brockmeyer, C.; Mendelsohn, A.L. Infant media exposure and toddler development. Archives of Pediatrics $\mathcal{E}$ Adolescent Medicine 2010, 164, 1105-1111.

11. Bathory, E.; Tomopoulos, S. Sleep regulation, physiology and development, sleep duration and patterns, and sleep hygiene in infants, toddlers, and preschool-age children. Current problems in pediatric and adolescent health care $2017,47,29-42$.

12. Fierman, A.H. Foreword: Sleep regulation, physiology and development, sleep duration and patterns, and sleep hygiene in infants, toddlers, and preschool age children. Current problems in pediatric and adolescent health care 2017, 47, 27-28.

13. Wright, K.; Lowry, C.; LeBourgeois, M. Circadian and wakefulness-sleep modulation of cognition in humans. Frontiers in Molecular Neuroscience 2012, 5. 
14. Knutson, K.L.; Phelan, J.; Paskow, M.J.; Roach, A.; Whiton, K.; Langer, G.; Hillygus, D.S.; Mokrzycki, M.; Broughton, W.A.; Chokroverty, S. The national sleep foundation's sleep health index. Sleep Health: Journal of the National Sleep Foundation 2017, 3, 234-240.

15. Matricciani, L.A.; Olds, T.S.; Blunden, S.; Rigney, G.; Williams, M.T. Never enough sleep: A brief history of sleep recommendations for children. Pediatrics 2012, 129, 548-556.

16. Kopasz, M.; Loessl, B.; Hornyak, M.; Riemann, D.; Nissen, C.; Piosczyk, H.; Voderholzer, U. Sleep and memory in healthy children and adolescents \&\#x2013; a critical review. Sleep Medicine Reviews 14, 167-177.

17. Sadeh, A. Consequences of sleep loss or sleep disruption in children. Sleep Medicine Clinics 2, 513-520.

18. Organization, W.H. Obesity and overweight [fact sheet; updated october 2017]. 2017.

19. Dehghan, M.; Akhtar-Danesh, N.; Merchant, A. Childhood obesity, prevalence and prevention. Heart Views 2006, 7, 74-82.

20. Sahoo, K.; Sahoo, B.; Choudhury, A.K.; Sofi, N.Y.; Kumar, R.; Bhadoria, A.S. Childhood obesity: Causes and consequences. Journal of Family Medicine and Primary Care 2015, 4, 187192.

21. 7. Obesity management for the treatment of type 2 diabetes: \&lt;em\&gt;standards of medical care in diabetes-2018\&lt;/em\&gt. Diabetes Care 2018, 41, S65.

22. Gubbels, J.; Kremers, S.; Stafleu, A.; Dagnelie, P.; De Vries, N.; Van Buuren, S.; Thijs, C. Child-care use and the association with body mass index and overweight in children from 7 months to 2 years of age. International Journal of Obesity 2010, 34, 1480.

23. Lifshitz, F. Obesity in children. Journal of Clinical Research in Pediatric Endocrinology 2008, 1, 53-60.

24. Li, S.; Jin, X.; Wu, S.; Jiang, F.; Yan, C.; Shen, X. The impact of media use on sleep patterns and sleep disorders among school-aged children in china. Sleep 2007, 30, 361-367.

25. Lemola, S.; Perkinson-Gloor, N.; Brand, S.; Dewald-Kaufmann, J.F.; Grob, A. Adolescents' electronic media use at night, sleep disturbance, and depressive symptoms in the smartphone age. Journal of youth and adolescence 2015, 44, 405-418.

26. Paavonen, E.J.; Pennonen, M.; Roine, M.; Valkonen, S.; Lahikainen, A.R. Tv exposure associated with sleep disturbances in 5-to 6-year-old children. Journal of sleep research 2006, 15, 154-161.

27. Brunborg, G.S.; Mentzoni, R.A.; Molde, H.; Myrseth, H.; Skouverøe, K.J.M.; Bjorvatn, B.; Pallesen, $\mathrm{S}$. The relationship between media use in the bedroom, sleep habits and symptoms of insomnia. Journal of sleep research 2011, 20, 569-575.

28. Ortega, F.B.; Chillón, P.; Ruiz, J.R.; Delgado, M.; Albers, U.; Álvarez-Granda, J.L.; Marcos, A.; Moreno, L.A.; Castillo, M.J. Sleep patterns in spanish adolescents: Associations with tv watching and leisure-time physical activity. European journal of applied physiology 2010, 110, 563-573.

29. Drescher, A.A.; Goodwin, J.L.; Silva, G.E.; Quan, S.F. Caffeine and screen time in adolescence: Associations with short sleep and obesity. Journal of Clinical Sleep Medicine : JCSM : Official Publication of the American Academy of Sleep Medicine 2011, 7, 337-342.

30. Lazarou, C.; Soteriades, E.S. Children's physical activity, tv watching and obesity in cyprus: The cykids study. European Journal of Public Health 2010, 20, 70-77. 
31. Schneider, M.; Dunton, G.F.; Cooper, D.M. Media use and obesity in adolescent females. Obesity 2007, 15, 2328-2335.

32. Maher, C.; Olds, T.S.; Eisenmann, J.C.; Dollman, J. Screen time is more strongly associated than physical activity with overweight and obesity in 9-to 16-year-old australians. Acta Pxdiatrica 2012, 101, 1170-1174.

33. Boone, J.E.; Gordon-Larsen, P.; Adair, L.S.; Popkin, B.M. Screen time and physical activity during adolescence: Longitudinal effects on obesity in young adulthood. International Journal of Behavioral Nutrition and Physical Activity 2007, 4, 26.

34. Kristiansen, H.; Júlíusson, P.B.; Eide, G.E.; Roelants, M.; Bjerknes, R. Tv viewing and obesity among norwegian children: The importance of parental education. Acta Paediatrica 2013, 102, 199-205.

35. Wethington, H.; Pan, L.; Sherry, B. The association of screen time, television in the bedroom, and obesity among school-aged youth: 2007 national survey of children's health. Journal of School Health 2013, 83, 573-581.

36. Jago, R.; Baranowski, T.; Baranowski, J.C.; Thompson, D.; Greaves, K.A. Bmi from 3-6 y of age is predicted by tv viewing and physical activity, not diet. International journal of obesity (2005) 2005, 29, 557-564.

37. Dennison, B.A.; Erb, T.A.; Jenkins, P.L. Television viewing and television in bedroom associated with overweight risk among low-income preschool children. Pediatrics 2002, 109, 1028-1035.

38. Owens, J.; Maxim, R.; McGuinn, M.; Nobile, C.; Msall, M.; Alario, A. Television-viewing habits and sleep disturbance in school children. Pediatrics 1999, 104, e27-e27.

39. Dennison, B.A.; Erb, T.A.; Jenkins, P.L. Television viewing and television in bedroom associated with overweight risk among low-income preschool children. Pediatrics 2002, 109, 1028-1035.

40. Vandewater, E.A.; Shim, M.-s.; Caplovitz, A.G. Linking obesity and activity level with children's television and video game use. Journal of Adolescence 2004, 27, 71-85.

41. Mattila, A.S. The impact of culture and gender on customer evaluations of service encounters. Journal of Hospitality $\mathcal{E}$ Tourism Research 2000, 24, 263-273.

42. Olafsdottir, S.; Berg, C.; Eiben, G.; Lanfer, A.; Reisch, L.; Ahrens, W.; Kourides, Y.; Molnar, D.; Moreno, L.A.; Siani, A., et al. Young children's screen activities, sweet drink consumption and anthropometry: Results from a prospective european study. European journal of clinical nutrition 2014, 68, 223-228.

43. Ansari, H.; Qorbani, M.; Rezaei, F.; Djalalinia, S.; Asadi, M.; Miranzadeh, S.; Motlagh, M.E.; Bayat, S.; Safiri, S.; Safari, O., et al. Association of birth weight with abdominal obesity and weight disorders in children and adolescents: The weight disorder survey of the caspian-iv study. Journal of cardiovascular and thoracic research 2017, 9, 140-146.

44. Amini, D.A.; Kannenberg, K.; Bodison, S.; Chang, P.; Colaianni, D.; Goodrich, B.; Lieberman, D. Occupational therapy practice framework: Domain \& process 3rd edition. American Journal of Occupational Therapy 2014, 68, S1-S48.

45. Magee, C.A.; Lee, J.; Vella, S.A. Bidirectional relationships between sleep duration and screen time in early childhood. JAMA Pediatrics 2014, 168, 465-470. 
46. Hale, L.; Guan, S. Screen time and sleep among school-aged children and adolescents: A systematic literature review. Sleep medicine reviews 2015, 21, 50-58.

47. Mak, Y.W.; Wu, C.S.T.; Hui, D.W.S.; Lam, S.P.; Tse, H.Y.; Yu, W.Y.; Wong, H.T. Association between screen viewing duration and sleep duration, sleep quality, and excessive daytime sleepiness among adolescents in hong kong. International Journal of Environmental Research and Public Health 2014, 11, 11201-11219.

48. Bickham, D.S.; Blood, E.A.; Walls, C.E.; Shrier, L.A.; Rich, M. Characteristics of screen media use associated with higher bmi in young adolescents. Pediatrics 2013, 131, 935-941.

49. Temple, J.L.; Giacomelli, A.M.; Kent, K.M.; Roemmich, J.N.; Epstein, L.H. Television watching increases motivated responding for food and energy intake in children-. The American Journal of Clinical Nutrition 2007, 85, 355-361.

50. Marshall, S.J.; Biddle, S.J.H.; Gorely, T.; Cameron, N.; Murdey, I. Relationships between media use, body fatness and physical activity in children and youth: A meta-analysis. International Journal Of Obesity 2004, 28, 1238.

51. Wilson, P.B.; Haegele, J.A.; Zhu, X. Mobility status as a predictor of obesity, physical activity, and screen time use among children aged 5-11 years in the united states. The Journal of pediatrics 2016, 176, 23-29. e21.

52. Kuriyan, R.; Bhat, S.; Thomas, T.; Vaz, M.; Kurpad, A.V. Television viewing and sleep are associated with overweight among urban and semi-urban south indian children. Nutrition Journal 2007, 6, 25.

53. Bickham, D.S.; Blood, E.A.; Walls, C.E.; Shrier, L.A.; Rich, M. Characteristics of screen media use associated with higher bmi in young adolescents. Pediatrics 2013, 131, 935-941.

54. Miller, M.A.; Kruisbrink, M.; Wallace, J.; Ji, C.; Cappuccio, F.P. Sleep duration and incidence of obesity in infants, children and adolescents: A systematic review and metaanalysis of prospective studies. Sleep 2018. 